\title{
Perspectiva de alteridad en estudiantes con ambientes de violencia y pobreza económica
}

\author{
Freddy González Silva ${ }^{\star}$
}

\section{Introducción}

Al desarrollar el tema de la alteridad se colocan en juicio distintas apreciaciones relacionadas con la diferencia. Entre ellas las definiciones del Diccionario de pensamiento contemporáneo (1997) y Aguilar (2005) que sitúan la alteridad en la perspectiva de la diferencia establecida entre humanos. Otra conceptualización complementaria es la de Téllez (1998) que argumenta además, que se construye mediante los tipos de relaciones simbólicas entre los individuos. Ante todo este entramado teórico cabe destacar que aunque se trate de una reflexión subjetiva genera una tipología de nuestras actitudes hacia lo otro (Theodosíadis, 1996). Dicho proceso inherente al ser humano se manifiesta en cualquier contexto cotidiano y puede a su vez pasar desapercibido por la mirada común.

Al ser la alteridad un proceso de comprensión que genera posturas en las personas puede servir de marco para comprender cualquier fenómeno de interacción humana. De allí que puedan examinarse problemáticas complejas en los ambientes más comprometidos dentro de cualquier contexto. De allí que para esta investigación se tomó la pobreza como estrato más genérico dentro de la América latina y la violencia como factor de relevancia en diversos centros escolares.

Cabe considerar, según el planteamiento de Rodríguez (2004), que la pobreza aparece unida indefectiblemente a la violencia como causa y expresión de injusticias, inequidades, postergación y exclusión social. Aunque es preciso reconocer que está desembocando en un aumento alarmante de los niveles de violencia en todos los estratos y niveles sociales. La pobreza, aunada a la violencia escolar, es fruto de una relación de la alteridad posiblemente inestable. Por lo demás, se comprende cómo la diferencia del otro es tomada como rechazo y remite a acciones agresivas.

En un estudio realizado sobre la violencia en el aula en Venezuela, Contreras (2007) ha demostrado que los diversos lugares de la edificación escolar, espacios para la convivencia y la socialización, no están exentos del surgimien-

Profesor de Psicología Social e Investigador en la UPS. E-mail: h.rodriguez@ups.edu.ec 
to de situaciones de conflicto expresadas mediante violencia o maltrato entre iguales. Cualquier alumno o alumna está propenso en una institución escolar venezolana a ser objeto de acciones violentas o de maltrato por parte de sus compañeros y compañeras.

En realidad, se desconocen las cifras exactas de la violencia escolar en Latinoamérica, pero sí se reconocen múltiples casos en los diversos ambientes. Para nadie es desconocida la cifra que cada semana reportan los diarios acerca de las muertes generadas principalmente en los ambientes de barrios pobres. Por ello, a la escuela como formadora de generaciones, le compete esta realidad y le toca jugar un nuevo rol en su proceso de gestación de un ciudadano integral. Expuesta esta situación, es necesario encontrar la alteridad en la prosecución escolar porque puede constituirse un factor que descubra nuevas aristas para el abordaje de la realidad.

¿Cómo integrar en un cuerpo teórico la expresión de alteridad que se genera en los actores fundamentales de la escuela a partir de la dinámica presente entre el alter ego?

\section{Método}

El presente estudio es de carácter cualitativo puesto que los insumos se recogieron a partir de la experiencia práctica anecdótica y la cotidianidad de los sujetos en torno a su otro. De esta forma se persigue lograr el objetivo de construir categorías hermenéuticas de alteridad a partir de las elaboraciones cognitivas generadas en las distintas etapas del desarrollo psicoevolutivo del estudiante. Cabe considerar que la investigación es de campo. Se explica, según el Manual de la UPEL (2006) como el análisis sistemático de los problemas de la realidad con el propósito de entender su naturaleza y actores constituyentes, además de interpretarlos.

Sujetos participantes. Se investigó la tercera parte de los estudiantes (135alumnos) de una escuela ubicada en un sector de pobreza económica llamado Bella Vista localizado en Venezuela. El muestreo fue de carácter intencional por ello se consideró solo un número de estudiantes que deseaban recibir atención del servicio de orientación. 
La técnica empleada se basó en la observación participante. Los instrumentos de recolección fueron: registro anecdótico y reportes verbales. El ámbito analizado fueron los estudiantes. El procedimiento siguió sesiones de profundidad dentro de las aulas y análisis de los insumos recolectados. Finalmente el instrumento de registro se realizó con filmaciones además del uso del papel y el lápiz.

\section{Análisis de los hallazgos}

En este apartado se presentan los hallazgos interpretados. Para ello se tomó un conjunto de oraciones, frases y palabras que, a través de un proceso de comparación y contrastación, dieron lugar a soportes teóricos. En efecto, a partir de una codificación selectiva de categorías y dimensiones se organizaron temas centrales y subtemas, en los que se alcanzaron proposiciones teoréticas, se profundizaron conceptos y se descubrieron relaciones genéricas que pueden evidenciarse a continuación.

\section{Registro anecdótico}

Se encontraron un conjunto de acciones que fueron resumidas y categorizadas en dos ámbitos de alteridad llamados alterados y equilibrados.

\section{Alteridad alterada:}

\section{Discriminación}

- Ante un sobrenombre puesto a un niño de la clase, otros se burlaban fuertemente. De esta forma se favorecía su descalificación (08-05-07).

- Cuando se colocó una fotografía de niños pobres de origen africano, alguien exclamó: "son todos negritos" (10-05-07).

- Esto denota la diferencia, puesto que nunca dicen lo mismo ante fotos de los niños blancos o rubios.

- El sobrenombre por parte de un directivo a un niño, diciéndole gordito delante de toda la escuela (por micrófono) (21-05-07).

- La generalización de la discriminación suele hacerse común. 
- Un niño afrodescendiente se asoma a un salón y todos lo echan. Luego otro le dice "vete morcilla..." (23-05-07).

- Hoy se escuchan sobrenombres como "malvada negra" (24-05-07).

- Hablando de la clase de autoestima, una alumna señalaba: "a mí no me gustan los negros" y veía indirectamente a uno de los niños afrodescendientes (28-05-07).

- Hay una afrodescendiente a la cual todas las niñas dijeron "negra" $\left(2^{\circ}\right.$. grado). Cuando en una sesión se consultaba: ¿qué no te agrada de ti mismo? Ellos respondieron también por ella: su pelo (30-05-07).

- Hoy un niño no podía abrazar a la compañera, señala la maestra por racismo. Él antes le dice, "no me toques, maldita negra" y colocaba cara de asco (31-05-07).

\section{Cosificación}

- Algunos niños de $5^{\circ}$. respondían a la pregunta: qué es el sexo: Son relaciones entre las personas cuando se van por ahí (14-05-07).

\section{Autarquía del yo}

- Un hermano de sangre le dice al otro: "estamos completos", para no integrarlo a su grupo (21-05-07).

\section{Tensión}

- Rechazo de un joven a toda la actividad escolar. Siente que lo van a matar, ya que lo asocian a un hermano de un malandro (21-05-07).

- Un niño le dijo a otro "hueso de pollo, pellejo de pollo". Es experto en colocar sobrenombres. Otro día vino con la cabeza rajada y cómo se burlaban de él, no quiso entrar a la escuela (21-05-07).

\section{Violencia}

- Hoy los niños de $2^{\circ}$. grado comentaban sobre los esposos que se emborrachan y les pegan a las mujeres y a los niños. Y también los que se buscan a otra mujer (31-05-07).

- Melisa $\left(6^{\circ}\right.$.) agarró a Cindy ( $4^{\circ}$.) por los pelos, y le dijo "por ser negrita". La humilló, ya que venía peinada (y le cuesta peinarse). Le destrozó su peinado (31-05-07). 
- Rizo y otro niño agarran la niña afrodescendiente para alborotarle su pelo (31-05-2007).

- “Maestro: ¿y por qué no matar a navajazo?” (31-05-07).

\section{Alteridad equilibrada:}

\section{Ética como unidad y aceptación}

- Un niño de $5^{\circ}$. manda de mala manera a quitar a un compañero que está sentado en un pupitre adelante. El otro no quiere y él por sí mismo quiere caerle a golpes; otro más grande levanta el pupitre para evitar problemas (17-05-07).

\section{Reciprocidad}

- Socializan ayudándose a realizar la actividad. Intercambian, se organizan, se atraen por las ideas comunes (21-05-2007).

- El común de ideas hace que unos puedan entrar en el mundo de los otros.

- Observo que la alteridad la maneja de acuerdo al número de palabras que ellos conocen en referencia del otro. Nota: entre 11 y 13 años les gusta mucho el test.

- Si la gente le manda a hacerle los mandaos a uno hay que obedecerle (10).

- Cuando van a robar le dicen al amigo espérame en tal sitio (10).

\section{Reportes verbales}

De igual forma que se analizó los insumos anteriores se categorizaron los reportes verbales. A continuación se presentan:

\section{Discriminación por descalificación}

La diferencia viene signada por los sobrenombres hacia su cabello, su peso, tamaño de partes de su cuerpo, color de la piel: siendo el más afectado el de origen afrodescendiente.

Me ponen de sobrenombre espagueti y yo les digo cabeza'e pollo (6). Marrana flaca, gorda panzona, gorda manteca. A ella le ponen María pichola (7). 
Cabeza'e gallina, a mí me dicen y que cabeza de mandarria, papo (7). A mí me dicen enano. A un niño sin diente le dicen vampiro, a uno muy flaquito le dicen esqueleto, huesito'e pollo, a una niña por la piel le dicen negra, cuando almorzamos caraotas dicen mira Karina (dirigiendo su mirada a los granos), también le llaman micrófono (cuando llevan moñito las afro) (7). Los otros niños no son mis amigos: dicen que no me cepillo, me dicen cállate negro cachumbambé. Al pelo'e chicharrón les digo cabeza de cotufa, otros niños me dicen cabeza de balón, cabeza de zapato, me dicen gordo (8). Me dicen caraota quemao. El único que no me dice sobrenombre es mi amigo. Yo nunca abuso y él tampoco. A veces nos decimos tonto (8).

Esto suscita un proceso de reflexión acerca del significado. "Cuando una gente me dice sobrenombre, pienso que está mal hecho porque si le digo un sobrenombre a él se molesta. La maestra me dice que quien pone sobrenombre a los demás se los pone a él mismo" (7).

La diferencia viene signada por los sobrenombres hacia su cabello, su peso, tamaño de partes de su cuerpo, color de la piel: siendo los más afectados los de origen afrodescendiente. Pero también aunque en menor cuantía a sus actitudes personales.

A los pequeños les pongo sobrenombre: "tuti, chiquitín". A él le dicen canela (9). Cabeza'e patilla, caraota piche (a los negros de primero y les doy lepe cuando se portan mal), cuero'e pollo (si son muy flacos), pelota o tute (si es muy gordo) (9). Caraota blanca, cabeza'e gorila, cabeza'e cola. A las niñas no pero a los varones sí. A mí me ponen gallo, rata, morrocoy (10). Le tienen el sobrenombre de caraota, cabeza'e pelota y cabeza'e tanque. Yo digo sobrenombres como: cabeza e pipote, cabeza'e perola, balón (10). Palito electrónico, ballena negra (gorda y negra), siete potencias (10). Cabeza'e pollo, cabeza de cebolla, cabeza de tortuga. A mí me dicen cabeza de tomate (10). Magú (si es enanito), golda cachucha, ojo de ganao (un ojo grande y otro pequeño), burro con sueño, miguelón, negro mojino, vampiro (por los colmillos), la chilindrina (es muy sensible), blanca nieves (si es muy blanca). A mí me dicen cabeza de extraterrestre (10). Le pone sobrenombre a otro niño tal como: Cabeza'e bala (si es grande), narizón, dumbo (si la oreja es grande). Otros niños le dicen enano (10). Paja larga (no sabe bateá) paco el flaco. A mí me dicen petróleo, muleca (10). Dienton, terminetor o cuatro pepas (si usa lentes), solomo. A mí me dicen lococagua, revolvedor 
(11). A veces yo soy el que le dice oreja de dumbo o chimenea a un compañero (11). Orejón, caraota (afro), agua negra (afro), pata'e foca (mal jugador), pata'e lancha, diente'e burra, radiografía (porque es muy flaquito), también la muerte (flaco), pelo'e cotufa, porque lo tiene churruscao, pelo'e chicharrón, diente sucio, cabeza'e tucusito. A mí me dicen enano, Sasha (una perrita pequeñita), pelo de hongo (11). Burritos, cotufa, chilindrina, mamao, cigarrón pelúo (a un afro descendiente) (11). Bemba (por la boca gruesa), boloña (a un niño gordito), a mí me dicen bombita de jugo (12).

Caga trailer (porque un chamito se cagó en un trailer), chepa candela. A mí me dicen chuchería (porque me dicen chucho) (12). El señor de las camionetas (porque anda siempre con la camisa rota), piñerúa, (porque es recoge lata), cabeza'e cuatro plantena, cabeza'e hacha, cabeza' e mamón chupao, oreja'e pocillo, pichón de tuqueque (es negro), pelo'e colchón y chicharrón (por pelo enrollaíto). A mí me dicen burro (porque a mi papá le decían así cuando pequeño) (13). Cabezón, tornillo'e reloj (porque es chiquita), indígena, frente de para choque. A mí me dicen PO (es una comics de un gordo), ballena asesina. Me da miedo la gente porque no las conozco. Lo que más le ha molestado es que le pongan un sobrenombre, le dicen: pepa carbón, negro cachumbambé, frente'e papa, coge yegua, y el sobrenombre que le pone a los demás es dumbo y leche (si es blanco) (13). Caraota quemá (si es negro), o te pasaste de horno, a burro (se la pasa sucio, descalzo), diente'e conejo, ñoño (si es gordito) (13). Sádico, lambucio. A mí me han puesto cochinopli (porque tengo la nariz como un cochino) (13). Oreja'e dumbo, oreja'e fogón, chimenea, cigarrón (si es negro), carota, pelo achicharrao, si se llama Carlo le pongo Carla, gordote. A mí me han dicho Oswaldo Guillén, pata pluma (porque no sabe patear el balón) (13). A mí me ponen cabeza'e bala (porque la cabeza la tengo así) (13). Chismosas, sifrinas, echonas, malandras, vaca o cochino (gordas), palitos (flaca), carbón o caraotas (negros). A mí me decían vampirito (por los dientes) (14). La mamporota (es gorda), cuajo'e gallina (es flaco), Justina (es flaca), pitillo, negro morao. A mí me dicen virolo (14). Rironesa, (se llama Vanesa) a un amigo le dicen ballena (14).

\section{Discriminación por rechazo}

Discrimina por acciones de violencia directamente enfocadas en sus pares:

Los que no me gustan es porque son malos: fastidian a las niñas, les pegan y les jalan los cabellos y nos pegan a nosotros (6). No me gustan los niños que me pegan a mí (6). No juego con algunos porque son malos conmigo: me dan 
cachetadas, me tumban pa'1 suelo y a veces tengo que correr porque me van a pegar una piedra o algo así (7).

La discriminación es sufrida por el rechazo de sus pares.

Hay niños que me rechazan, me dicen feo y malcriado (6). No tengo amigos porque no quieren ser mis amigos (6). Los niños me rechazan, no quieren jugar conmigo, me dicen que no sé batear. Una vez la atajé y me dieron que era un out. Yo les dije que no y la ataje y me dijeron "no, no seas tan loco" (8).

Se evidencia la etnodiscriminación.

Hay niños que no me caen bien, un negro porque es negro, parece que tiene sucia la cara y no se baña. Hay blancos que roban metra y me culpan a mí (10). Son carajitos malos. Feos, con la cara negra (10). "No me gustan las personas negras, me caen mal, no me las llevo bien con ellas" (11, esta niña es también afrodescendiente).

La discriminación por el rechazo hacia acciones violentas dirigidas a su ego.

La gente que no me gusta es aquella que le gritan a uno. Señores que no respetan, me han hecho maldad, que cuando juego metra me las agarran y las botan, en la calle. Me pegan sin hacerles nada (10).

También por el peligro que pueden generar a su propio ego.

No me junto con malandros porque matan a uno y le mandan a fumar drogas. Lo mandan a robar a uno y si uno los descubren lo matan a uno (9). Las personas que a mí no me gustan son las que consumen drogas y son flacos... A mí me han rechazado los malandros, porque me la paso en el campo (10). Excluyó las personas que vienen y siempre andan luciéndose, siempre andan bebiendo por ahí, tampoco me gustan las que sufren (13). Hay personas que lo han rechazado pero no saben porque, sus vecinos del frente los odian (13). Excluyo las dañadas, las que inventan cosas malas y las sifrinas que no me las llevo bien (14). No me gusta la gente egoísta. Me guste la gente que brinque y salte, no la gente que lleve la contaría (13). No me gustan los drogadictos porque ellos provocan a uno al vicio, luego uno tiene que estar comprando, los alcohólicos es como las drogas, los malandros porque provocan a uno al robo, le ocasionan mucho problema porque uno puede robar hasta su propia familia y le botan de su casa. La gente tiene valor, pero esas personas no son nada mío para que me estén diciendo (14). 


\section{Tensión}

Los momentos de tensión son reconocidos cuando se les hizo violencia.

Me pongo bravo cuando alguno me mete golpes y me rompió la boca (6). Me pongo bravo cuando me quitan mi arepa, jugo, mi agua... Me pongo brava cuando mi mamá y mi hermana me pegan (7). Me pongo bravo cuando mi papá me pega y mi tío Tony también (7). Si yo les digo algo le caen a golpes a uno. Me pongo bravo cuando me dicen groserías: cállate, gafo, come huevo de gallina, care'e culo, niñita (8).

Los momentos de tensión son reconocidos cuando se les hizo violencia.

Cuando me dicen groserías les doy por la cara. Como me pasó ayer con oreja de dumbo (9). Me hace poner muy bravo que me estén pegando y me pongan sobrenombre (10). Cuando me pegan me pongo bravo. Si es un niñito le lanzo una piedra (10). Me ha fastidiado un compañero de clases que me pega, o me dice groserías: "mama guevo" (11). Me gusta la gente que no se ríe de los demás (11). Gente que pelee con uno y le diga grosería (11). No me gusta que me regañen y digan lo que no es que me estén diciendo grosería y me estén fastidiando con piedritas (11). No me gusta la gente que le quita a uno las cosas (11).

También se genera tensión al pensar en lo que simbolizarían sus actos futuros.

Me pongo tenso pensando, hago algo "si quiebro un plato mi mamá me pela" (y me muestra su mano). Si me ensucio en la calle (9). O por recuerdos. Ahora me puse bravo porque no me pagaron una deuda y cuando mi papá no me llevó pa'la playa (11). Cuando insultan a mi abuelo (que ya está muerto) o mi mamá, me pongo tenso y busco pelear. Si me empujan o dan golpe me defiendo (12). Me molesta que me digan groserías, ejemplo: "mama huevo" y maldito. Son busca 'peo': le dan 'lepe' a uno, le dan 'patá'. Me dan golpe y les caigo a coñazo (13). Cuando se separan los niños se ponen a llorar (13). Cuando me golpean o me dicen algo cada ratico me molesto y me pongo tenso (14). Lo que la pone brava es que le tiren la puerta (14). A mí me molesta todo, yo soy amargado (14). Me empiezan a buscar problemas tirándome piedras, conchas de cambur, empujándome algunas veces y entonces yo me quedo tranquilo y otras peleo a golpes (12). Hay veces que me regañan sin razón porque alguien te busca problemas y le responde con golpes (12). Le parto la cara si se meten conmigo, si me chantajean: "te voy a jodé, a partí la cara"... Me le voy encima si me dicen 
coño'e tu madre (13). Se cayó a golpe porque otro niño estaba abusando, cuando uno está tranquilo y otro quiere jugar dando golpes (13). Se pone bravo cuando se meten con su familia. También señala que se molestan cuando lo empujan. Y se cae a golpe (13).

\section{Ecpatía}

Un señor buscaba a mi mamá y ella le dijo que no pasara, estaba pidiéndole comía. Una señora que tiene sombrilla mi amá no la pasa, no habla con ella. Un señor pasa con una revista y mi mamá lo deja pasar, habla de Dios (7). Peleo cuando juego metra y me hacen trampa (9). Uno no entiende las personas porque no le hablan bien (10). No tengo amigas, porque empiezan a pelear conmigo. $\mathrm{Me}$ acusan de agarrar las cosas sin permiso, a pesar de que les pide permiso a ellas. Cambió de colegio cuatro veces y los niños en otras escuelas eran chévere. Aquí es que se meten con ella (11). Se relaciona difícilmente con los demás, según ella dice, y no sabe por qué. Siente que los otros son egoístas, no saben compartir con los demás y no saben ayudarse entre ellos mismos (11, es afrodescendiente). Critico a una persona porque le tengo rabia, porque son muy chismosos, habla paja (13). Las más difíciles de comprender son las chismosas, en el caso de mi tío, le dijeron que yo le saqué la gallina del corral (13). No me caen bien las personas que ven a uno con una mala cara (14).

\section{Autarquía}

A mí no me gusta intercambiar porque después cree que es cosa mala, que no les gustará después y se les devuelve al que se lo dio (10). Me gusta obligar a otros a que vayan conmigo pa' donde yo voy (13). A mí no me tiene que mandar nadie, yo me mando solo. Nadie lo puede mandar porque no es su sangre (14).

\section{Cosificación}

No soy responsable de nadie, cada quien que asuma su responsabilidad (9). No soy responsable con los otros porque ellos se tienen que cuidar (10). No soy responsable de los demás (10). No soy responsable de los demás porque ellos se están cuidando solos (10). 


\section{Utilitarismo}

Con algunas personas soy bueno, porque juego metra con ellos (9).

\section{Responsabilidad}

Es atribuida a los pares y a los familiares. En la única persona que pienso es en mi hermano, pienso que siempre lo voy a estar cuidando (10). Soy responsable de mi hermana, si se porta mal no la dejo salir (9). Soy responsable de los demás cuando me los dejan cuidando (10). Soy responsable de otros niños cuando los están jodiendo y yo los desaparto (10). Me siento responsable de cuidar al pequeño de que no haga cosas malas y se porte bien. La gente que más me gusta es mi familia (11). Soy responsable de los que andan conmigo (11). A veces me siento responsable de los demás, cuando me tratan bien a mí y yo bien a ellos. Cuando no me gusta trabajar con una persona es porque sea grosera o mala no soy responsable (13).

\section{Empatía}

¿Tú podrías ser como tu tío? Sí porque dormimos en su mismo cuarto. No nos parecemos, mi tío es blanco, pero ambos tenemos un remolino en el pelo (8). Primas, tías, abuela, hermanos (papá y abuelo en el cielo) (8). Los malandros no tienen nada que ponerse y le gusta quitar las cosas a uno (10). Los malandros son así porque vieron son así porque vieron a otro y ellos se antojaron de la droga (10). Depende de uno ser malo o bueno y si estudia, no hay necesidad de estar robando camioneta (14).

\section{Reciprocidad}

La reciprocidad se entiende directamente a través de sus pares. Tengo amiguitos, les doy galletas, jugo, jugamos metras trampas y hacemos las tareas (7). Todos los niños me cambian cosas, por eso no peleo con ninguno (7). Vista por el intercambio de necesidades. Yo intercambio ropa con juguetes (9). Yo comparto chupetas, oreos, a mí me dan galletas, bubalú, frescos (10). Yo intercambio zapatos o chancletas (11). Intercambia chucherías, ropa, caramelo, dinero (11). He intercambiado chucherías (12). Intercambia: lápiz, borra, nos prestamos las cosas, no nos negamos (12). Intercambio una bicicleta por otra. Son bien porque me emprestan, van pa' la casa a pedir prestado. Se emprestan algo y luego se lo entregan como se lo 
prestaron (13). Intercambian camisas, pulseras, gorras, zarcillos (14). Yo intercambio cuando presto que si mis libros, lo que la persona necesita (14).

\section{Tolerancia}

El único que no se burla es mi amigo Yumraimer: él es buena persona y compartimos todo: helados y otras comidas; es flaquito y usa pinchos, a veces nos chalequeamos y luego volvemos a ser amigos (8). Si me pegan les caigo a coñazos y luego los perdono al siguiente día (10). Soy comprensivo con los demás porque los trato bien (13). Se incorpora el perdón. Los amigos se portan bien con uno. Un día si le digo una grosería a un amigo y luego si le pido disculpa me perdona (13).

\section{Encuentro}

Búsqueda del encuentro.

Cuando estoy solo me ajunto (6). Yo hablo con otros cuando no quieren jugar conmigo. Si no se juntan le digo al profe y se juntan rapidito (7). Le tengo rabia a la que vive en mi casa porque peleó con mi mamá (su guía para interactuar es lo que le dice la madre). Con la persona con que mi mamá se peleó yo soñé que se tomaban la mano (7). Cuando me encuentro con alguien siento que vamos a ser amigos, a echar broma (10).

Cuando me encuentro con otra persona me siento bien porque nos las vamos a pasar jugando metra (10). Hay gente que me cae bien como José Manuel. Cuando uno de los dos trae algo siempre lo comparte con el otro (11). Si no conozco a alguien me siento apenado, como tímido (11). Al encontrarse con otros me alegro porque conozco otros de mis hermanos "Todos no somos hermanos" (11). Cuando me encuentro con una persona me siento apenado porque nunca la he visto (13).

De todos los insumos recolectados se logró la compactación de la información en la gráfica a continuación: 
Gráfico 1. Manifestaciones de la alteridad

\section{Alteridad alterada o desvinculante}

\begin{tabular}{|c|c|c|c|}
\hline \multirow{9}{*}{$\begin{array}{l}\text { Discriminación } \\
\text { por descalificación }\end{array}$} & \multicolumn{3}{|l|}{ (De su ropa } \\
\hline & Cabello & & A la violencia \\
\hline & Peso & & Al afro \\
\hline & Tamaño de partes del cuerpo & & \\
\hline & Tamaño del cuerpo tota & por rechazo & Al que sufre \\
\hline & Color de piel: afro & o exclusión & Drogadictos \\
\hline & Defectoc fícises & & Egoistas \\
\hline & 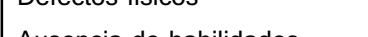 & & Los que se creen superiores \\
\hline & $\begin{array}{l}\text { Ausencla de habilidades } \\
\text { Acciones o maneras de actuar }\end{array}$ & & Alcohólicos \\
\hline
\end{tabular}

Tensión $\left\{\begin{array}{l}\text { Por robos } \\ \text { Violencia } \\ \text { Ofensas } \\ \text { Hacia sus actos futuros } \\ \text { Por recuerdos de traición } \\ \text { Aumenta a medida } \\ \text { que son adolescentes }\end{array}\right.$

Ecpatía $\left\{\begin{array}{l}\text { Hacia otras religiones } \\ \text { Con el chismoso } \\ \text { El hambriento }\end{array}\right.$

Cosificación $\left\{\begin{array}{l}\text { No existe responsabilidad } \\ \text { hacia él otro }\end{array}\right.$

Utilitarismo | Sólo sirve para jugar

Autarquía $\left\{\begin{array}{l}\text { Egoísmo de compartir } \\ \text { Imponer su voluntad }\end{array}\right.$

\section{Alteridad equilibrada o próxima}

Tolerancia $\left\{\begin{array}{l}\text { Con acciones de sus amigos } \\ \text { Perdón ante la violencia }\end{array}\right.$

Reciprocidad $\mid \begin{aligned} & \text { Alimentos } \\ & \text { Ropa, juguetes y libros }\end{aligned}$

$$
\text { Empatía }\left\{\begin{array}{l}
\text { Con la familia } \\
\text { Con malandros }
\end{array}\right.
$$

Encuentro $\left\{\begin{array}{l}\text { Con la familia } \\ \text { Con los de su edad }\end{array}\right.$

$$
\text { Responsabilidad }\left\{\begin{array}{l}
\text { Por necesidad de amigos } \\
\text { Por juego } \\
\text { Por risas } \\
\text { Por fraternidad } \\
\text { Pena }
\end{array}\right.
$$




\section{Interpretación}

\section{Las manifestaciones de la alteridad}

El análisis precedente permitió explicitar que es posible aproximarse a la condición de alteridad a través de las creencias de cada persona, sus sentimientos y símbolos. Sin embargo, además de los reportes verbales se encuentran las conductas. Ambos, desde la perspectiva de González (2006), representarían el desarrollo de los llamados pilares distantes e instantes.

Así pues, gracias a esta investigación se pudo compendiar un conjunto de manifestaciones que han sido subdivididas en expresiones saludables de la alteridad y perjudiciales de ella. Unas u otras tienen que ver con lo positivo y lo negativo de aquella. En efecto, se encontraron manifestaciones de alteridad alterada o desvinculante, entre los cuales destacan dos tipos de discriminación.

La discriminación por descalificación consiste en distinguir peyorativamente al alter por su forma de vestir, su cabello (principalmente si era afro), el peso (gordo o flaco), el tamaño de las partes de su cuerpo, su corporeidad en general, color de piel (si era afro), defectos físicos, ausencia de habilidades, acciones o la personalidad. Aunado a esto se encontró en el caso de los docentes una diferenciación crítica hacia el sexo opuesto y la estética.

El otro caso es el de la discriminación por rechazo o exclusión, acción centrada a la violencia, al afrodescendiente, al malandro, al que sufre, al drogadicto, al egoísmo, al que se cree superior y al alcohólico.

Existe una alteridad desvinculante expresada por la tensión. El yo escolar de los estudiantes manifestó angustia por los robos y las ofensas. La tensión también se expresó por el desconocimiento ocasionado por la incertidumbre hacia sus acciones futuras y el no saber qué hacer, además de recuerdos de traición. En el caso de los docentes, fue atribuida al cumplimiento de acciones por obligación.

Otra manifestación de alteridad alterada fue la ecpatía por el otro. Sin duda se dirigió a los de religiones distintas, a las personas chismosas y a los hambrientos. Los docentes la interpretaron como fruto del desinterés. 
Algunas de sus manifestaciones en menor expresión fueron por: cosificación al no sentir ninguna responsabilidad por el alter; utilitarismo (solo sirven para jugar), autarquía (egoísmo para compartir sus cosas y deseo de imponer su voluntad sobre los demás). Finalmente, y no menos importante, la violencia expresada en gritos, bulla, peleas, maltratos y golpes dentro del ámbito escolar.

En otro orden de ideas está la alteridad vinculante o equilibrada, expresada en la tolerancia frente las acciones de sus amigos y el perdón ante las situaciones de violencia. Así mismo, la empatía con la familia, con los malandros y con los iguales. Algunos maestros señalaban sentir empatía por obligación como un recurso para acercarse al otro.

De manera similar se encontró la reciprocidad. Ésta se expresó en los niños a partir de intercambio de sus alimentos, ropa, juguetes y libros. En el caso de los docentes se presentó con respecto a la imagen del otro y en la personalidad del otro en sí. En esta misma perspectiva se ubicó la responsabilidad por el otro, bien sea por la necesidad de amigos, por el juego, las risas y la fraternidad. Los docentes se sintieron responsables por la acción de enseñar y el deber de proteger.

También se presentó la complementariedad. Esta manifestación de alteridad fue descubierta en los docentes quienes la expresaron como la cohesión con el otro, la ayuda entre pares, la similitud y la comunicación.

Finalmente, en esta forma de alteridad próxima, se registró el encuentro principalmente vivido en compañía de las personas contemporáneas en edad. Además de ello, la alteridad hacia la familia y principalmente respecto a la madre.

En el proceso de investigación que produjo el sintagma gnoseológico pudo reconocerse que la alteridad era manifiesta en discriminación, tensión y encuentro (Diccionario de pensamiento contemporáneo, 1997) o desde la perspectiva de Aguilar (2005) en tres maneras distintas de tomar la alteridad: 1. El otro abyecto al que se toma en cuenta para rechazarlo o excluirlo; 2. El otro como lugar donde se constituye el yo; y, 3. Incluir al otro en lugar de excluirlo. Este estudio permitió reordenar las manifestaciones de alteridad conocidas y las presentadas en los hallazgos. A partir de allí surgieron, en consecuencia, dos grandes categorías que se 
explicitaron y agruparon en la alteridad alterada o desvinculante y en la equilibrada o próxima.

\section{Conclusión}

El presente estudio permitió asociar la las relaciones "yo-tu" con manifestaciones existentes en el campo educativo. De esta forma se integró este fenómeno desde un cuerpo teórico que subdivide la alteridad en desvinculante y próxima. Allí se gestaron las dimensiones que pueden ser empleadas por futuros estudiosos para desarrollar nuevas vías de atención.

Todo ello permite propiciar una intervención distinta dentro de la escuela. Esta investigación arroja nuevas maniobras para la atención de los estudiantes. Los docentes pueden empezar a trabajar la idea de acercar los estudiantes a un mundo más socializado y de convivencia a partir de la reflexión intersubjetiva de alteridad. No se trata de simplemente conversar el asunto, sino de propiciar reflexiones en los estudiantes. El solo hecho de tomar conciencia de esta arista de la problemática actual ayudará a asumir nuevas posturas.

A los padres se les agradece preguntar constantemente a sus hijos qué sentido tienen su maestro y sus compañeros en su vida. Dicho cuestionamiento debe ser constante, porque será como una guía que les permita identificar el comportamiento de proxemía o de desvinculación de su hijo hacia quienes le rodean.

\section{Referencias bibliográficas}

\section{Textos}

Aguilar Rivero, Mariflor. Diálogo y alteridad. Trazos de la hermenéutica de Gadamer. México: UNAM. 2005

Diccionario de pensamiento contemporáneo (1997). Madrid: San Pablo. 1997. González, F. "El estudiante asperger una comprensión desde el enfoque de la alteridad". Revista educere, 35. 611-620. 2006. 
Rodríguez, Francisco. "La pobreza como un proceso de violencia estructural". Revista de ciencias sociales, 10(1), 42-50. 2004.

Téllez, M. "Desde la alteridad: notas para pensar la educación de otro modo". RELEA, 5, 119-145. 1998.

Theodosíadis, F. Alteridad ¿la (des)construcción del otro? Bogotá: Magisterio. 1996.

UPEL. Manual de trabajos de grado de especialización y maestría y tesis doctorales. Caracas: FEDUPEL. 2006.

\section{Sitios web}

Contreras, Azael. "Hacia una comprensión de la violencia o maltrato entre iguales en la escuela y el aula". Revista ORBIS / Ciencias Humanas [Revista en línea] 6. Disponible: <http://www.revistaorbis.org.ve/6/6Art5.pdf> [Consulta: 2008, Febrero 5]. 2007. 